\title{
Assessing non-detrimental trade for a CITES Appendix II-listed plant species: the status of wild and cultivated Galanthus woronowii in Georgia
}

\author{
H. Noel McGough, David Kikodze, Richard Wilford, Lucy Garrett \\ Grigol Deisadze, Natalie Jaworska and Matthew J. Smith
}

\begin{abstract}
A process for the review of significant trade in species listed in CITES Appendix II was established to address problems with the application of CITES Article IV. Article IV states that international trade in Appendix II species requires a Scientific Authority of the state of export to determine that such trade will not be detrimental to the species' survival in the wild. Such a review process was initiated for the plant species Galanthus woronowii Losinsk. as a result of continuing uncertainty over the sustainability of international exports of the plant from wild populations in Georgia, and the Georgian Management Authority was tasked with determining and reporting whether export levels conformed to Article IV. Here we report on the project that was established to address that task. Nationwide field surveys conducted in 2009 led to the recommendation of a conservative annual export quota of 15 million plants for the sites surveyed. Cultivated populations held significant stocks of harvestable plants but with varied cultivation histories, especially in relation to the extent and nature of supplementary planting. Future work should continue to monitor harvesting from wild populations and identify solutions for local communities wishing to cultivate the plant for international trade.
\end{abstract}

Keywords Appendix II species, CITES, Galanthus woronowii, Georgia, non-detrimental trade, review of significant trade

This paper contains supplementary material that can be found online at http://journals.cambridge.org

H. Noel McGough, Richard Wilford, Lucy GarretT* and Natalie JaWorska Royal Botanic Gardens Kew, Richmond, Surrey, UK

DAVID KIKODZE, Institute of Botany, Ilia State University, Tbilisi, Georgia GRIgOl DeISADZE, National Botanical Garden of Georgia, Tbilisi, Georgia

Matthew J. Smith (Corresponding author) Microsoft Research, 21 Station Road, Cambridge, CB1 2FB, UK. E-mail matthew.smith@microsoft.com

*Also at: School of International Development, University of East Anglia, Norwich, UK

Received 6 July 2012. Revision requested 18 October 2012.

Accepted 9 January 2013. First published online 17 February 2014.

\section{Introduction}

The Convention on International Trade in Endangered 1 Species of Wild Fauna and Flora (CITES) is an international agreement intended to ensure that international trade in species does not threaten their survival in the wild (CITES, 1973). For international trade in wild-harvested species listed in Appendix II, Article IV of the Convention requires that a Scientific Authority of the state of export advises that export will not be detrimental to the survival of the species in the wild. This non-detriment finding is at the core of ensuring that trade of CITES-listed species is sustainable, and problems relating to the implementation of Article IV are addressed by a process known as the Review of Significant Trade in Specimens of Appendix-II species, (CITES, 2012a). Here we report on the application of this process to the international trade in the Appendix II plant species Galanthus woronowii Losinsk. from Georgia.

Baseline knowledge of the biology and status of the taxon and well-codified adaptive species management schemes are characteristic of effective wild-harvest management systems for CITES-listed taxa (Rosser \& Haywood, 2002). For example, for plant species such as ginseng (Ford, 2008) and mahogany (Grogan \& Schulze, 2008) such management can include monitoring the status of harvested populations, the amount and condition of harvested individuals or their parts, and various other factors that influence the supply and demand of the harvested product (such as the market price or the intensity of illegal trade).

In Turkey harvested and unharvested wild populations of Galanthus elwesii Hook.f. and G. woronowii are monitored by members of the Scientific Authority and inspections are also performed at a central warehouse to gather information on the harvested plants (Yüzbaşioğlu, 2008). Under this management system millions of wild plants have been exported annually for over a decade without any evidence of detrimental effects.

In contrast, Georgia has exported higher quantities of $G$. woronowii for international trade (mean export of 15 million plants per annum during 2000-2010 compared with mean export of 2 million plants per annum from Turkey over the same period), with exports consisting of live plants (in the dormant stage as bulbs) to supply the horticulture industry. Uncertainty about the sustainability of these exports has caused concern amongst the 


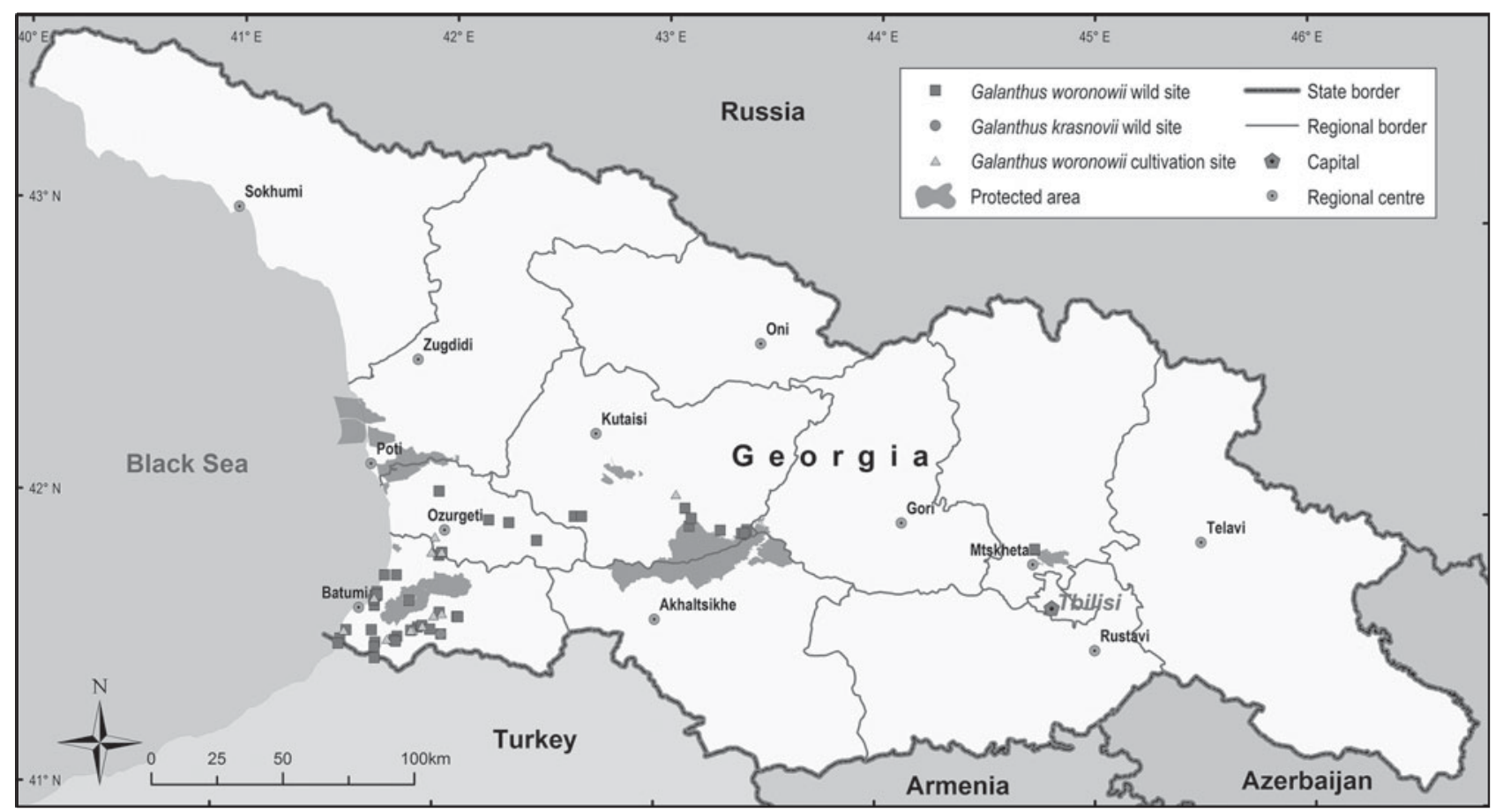

FIG. 1 Locations of the wild and cultivated populations of Galanthus woronowii surveyed in this study.

international CITES community for over a decade (Supplementary Material 1 gives a detailed historical background of international trade in Galanthus spp. from Georgia). It was reported at the International Expert Workshop on CITES Non-Detriment Findings (CONABIO, 2008) that neither a formal management plan nor an effective monitoring system had been established to ensure sustainable trade and conservation of wild populations (Kikodze, 2008). Here we outline the results of the CITES Significant Trade project that was formally commissioned to address the concerns of the international CITES community (Kikodze et al., 2009; PC, 2011).

\section{Methods}

\section{National survey of wild populations}

In 2009 the Georgian Authorities arranged for a nationwide survey to assess the status of their major populations of G. woronowii. During February-April 2009 we conducted field surveys at 41 sites throughout Georgia (Fig. 1). The territory of Abkhazia was not included because of political unrest. The surveys included some populations in seminatural habitats (wild areas in Batumi Botanic Garden) and in agricultural habitats (citrus and bamboo plantations). The majority of the study sites were in the Ajara Autonomous Republic, where the largest populations of G. woronowii are known to occur. The population distribution in this region extends along the Black Sea coast to Abkhazia and southern Russia in the north and north-east Turkey in the south, with rare populations occurring in the Central Caucasus (Bishop et al., 2001). At each site we recorded the density of plants, site area, vegetation type and location (with a global positioning system). We assessed the conservation value of each site in terms of species richness, degree of naturalness and anthropogenic disturbance, and uniqueness of the habitat (Table 1), and the density of plants at each site, using quadrat sampling. The number of leaves per quadrat was used as a quantitative index of plant density because leaves are easily recognizable and countable in situ. At the time of surveying most plants possessed one pair of leaves, although some had one or three leaves. A $0.5 \times 0.5 \mathrm{~m}$ quadrat was chosen based on a preliminary analysis of a suitable size to efficiently estimate plant density per site. A preliminary survey of a wild population covering 3.5 ha close to Batumi was used to estimate the typical variation in counts (Greenwood \& Robinson, 2006). This led to the decision to survey at least 20 quadrats per site within an area of c. 1 ha. This was subsequently increased to 25 quadrats for the wild sites when it was found that the variance of the estimates was higher for these sites.

\section{Surveys of cultivated populations}

In 2009 we also conducted surveys at sites that had been specifically managed (in part) to cultivate G. woronowii (hereafter referred to as cultivated populations). Each survey consisted of an interview with the landowner or local government representative, to obtain historical information, and a field survey similar to those performed for the wild 
TABLE 1 Criteria used to assess the conservation value of 41 field survey sites in Georgia (Fig. 1).

\begin{tabular}{|c|c|c|c|}
\hline \multirow[b]{2}{*}{ Criterion } & \multicolumn{3}{|l|}{ Conservation value } \\
\hline & High & Medium & Low \\
\hline Species richness & $\begin{array}{l}\text { High species richness noted or likely to occur; } \\
\text { endemic or threatened species included in the } \\
\text { Georgian Red Data Book \&/or IUCN Red List } \\
\text { recorded or likely to be present }\end{array}$ & $\begin{array}{l}\text { Medium species richness; few } \\
\text { rare or threatened species }\end{array}$ & $\begin{array}{l}\text { Low species richness \& } \\
\text { almost no threatened species }\end{array}$ \\
\hline $\begin{array}{l}\text { Naturalness \& level } \\
\text { of modification }\end{array}$ & Natural or slightly modified habitats & $\begin{array}{l}\text { Moderately modified habitats; } \\
\text { e.g. can still support } \\
\text { characteristic species } \\
\text { assemblages }\end{array}$ & Heavily modified habitats \\
\hline Human disturbance & Very little or no human disturbance & Little human disturbance & $\begin{array}{l}\text { Moderate to high human } \\
\text { disturbance (heavy } \\
\text { grazing, tree felling, etc.) }\end{array}$ \\
\hline $\begin{array}{l}\text { Rarity \& geographical } \\
\text { location of habitat }\end{array}$ & $\begin{array}{l}\text { Rare or threatened habitat in the country } \\
\text { or region; habitat within conservation } \\
\text { centres \&/or in the immediate vicinity } \\
\text { of protected areas }\end{array}$ & $\begin{array}{l}\text { Uncommon habitat in the region } \\
\text { but not rare or threatened }\end{array}$ & $\begin{array}{l}\text { Common habitat; areas } \\
\text { near human settlements }\end{array}$ \\
\hline
\end{tabular}

populations. The interviews were particularly targeted at revealing the origins of the parent stock and the cultivation sites, the degree to which supplementary planting from wild populations occurred and the status of the source wild populations, to deduce the extent to which bulbs harvested from the cultivation sites might be considered to be artificially propagated. Quadrat sampling was limited to $200.5 \times 0.5 \mathrm{~m}$ quadrats per site, based on the preliminary survey results.

Initial selection of cultivation sites was facilitated by analyses of historical data provided by the Georgian Ministry of Environment Protection and Natural Resources, which yielded the estimated areas of 87 cultivation sites and the expected weight of harvest $(\mathrm{kg})$ in 2006. On this basis we selected sites and areas that we expected to be typical in terms of yield ( $\mathrm{kg}$ bulbs ha $^{-1}$ ) as well as sites that appeared to be highly productive or very poor.

Fifteen sites were inspected in detail in 2009: one in Imereti, one in Guria and 13 in Ajara (Fig. 2). Fourteen sites were visited in 2010, after the submission of the final report to the CITES Plants Committee. Six of these had been visited in 2009 and eight were new sites, seven in Ajara and one in Mtskheta-Mtianeti.

\section{Precautionary projections of abundance}

We extrapolated quadrat counts of leaf density to national estimates of exportable bulbs to assess the possible sustainability of historic export levels and identify a precautionary export quota. To conform to the precautionary principle we applied precaution at each stage of these extrapolations. This was partly to enable us to deduce whether the historic export levels could be sustainable, even given these precautions, and partly to provide a mechanism whereby investigations could justify less precautionary (potentially larger) quotas in future, by assessing the accuracy of each specific assumption.

We used the lower $95 \%$ confidence interval of the mean number of leaves per quadrat as the leaf density value for each site to obtain a precautionary estimate in light of uncertainty regarding the true mean density. We then made a number of additional assumptions to scale up these figures to numbers of export-sized bulbs per site: (1) For cultivated sites the lower $95 \%$ confidence interval of mean number of leaves per quadrat was multiplied by the estimated site area to estimate the mean number of leaves per site. For wild sites this was further multiplied by a factor of 0.5 to counteract potential biases arising, for two reasons. Firstly, only a small fraction of the estimated area of most wild sites was sampled. It is possible that sampling was biased towards the densest, most noticeable patches and the unsurveyed area had significant areas of patches of lower density (based on our subsequent experience with surveying larger wild populations). Secondly, some wild populations were notably patchy, with populations arranged into high-density patches separated by low-density patches. Subsequent surveys at one of these sites, using quadrats of different sizes, indicated that smaller quadrats yielded higher density estimates, which suggests a sampling bias towards denser patches. Further research is therefore needed to identify the optimal sampling design for wild sites. (2) The number of plants per site was estimated as half the estimated number of leaves per site. Most plants had two leaves, with some plants having one or three leaves. (3) Plants need to have bulbs $>5 \mathrm{~cm}$ in circumference to be suitable for export. The number of plants with exportable bulbs was estimated as half the estimated number of plants per site. Occasional analyses indicated that the majority of sampled plants tended to have exportable bulbs but we took a precautionary estimate because our preliminary assessment of the number of 

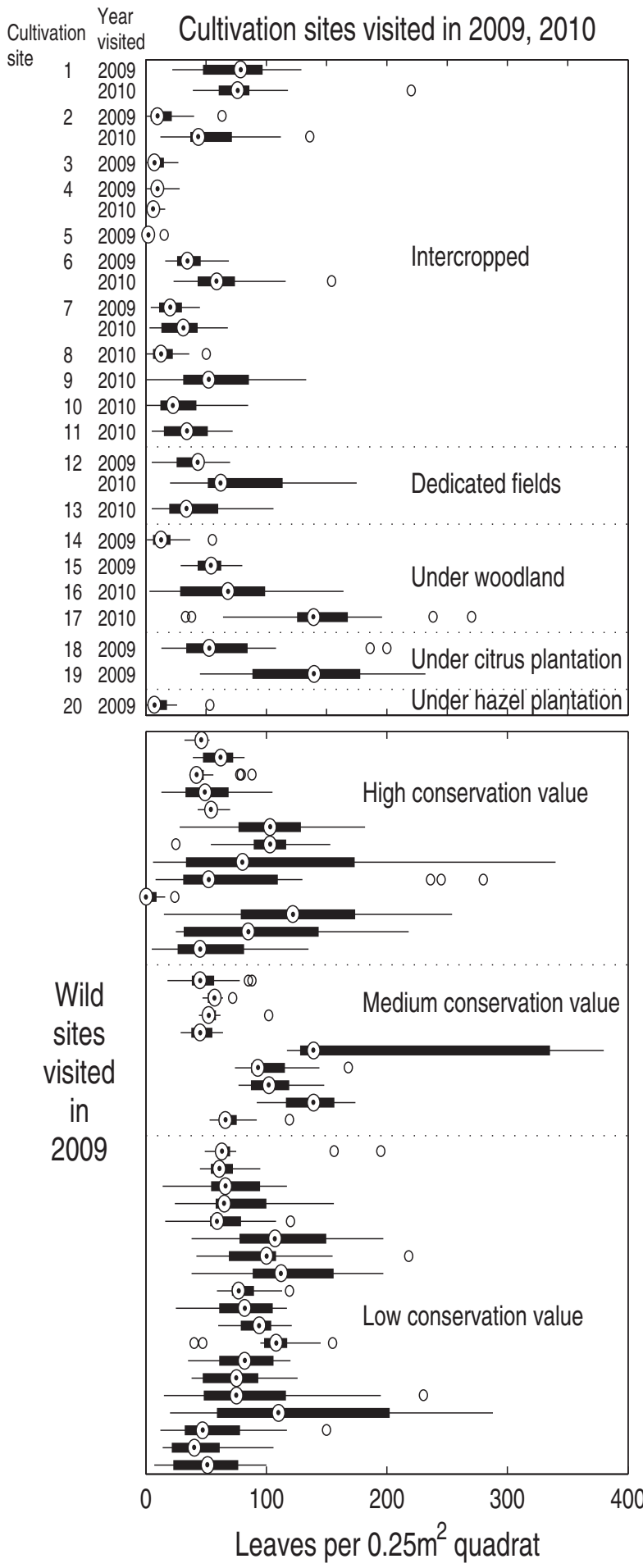

FIG. 2 Distributions of leaf counts per quadrat $\left(0.25 \mathrm{~m}^{2}\right)$ for the cultivation sites surveyed in 2009 and 2010 and the wild sites surveyed in 2009. Black points are medians, boxes bound the 1st and 3 rd quartiles, whiskers approximate $99 \%$ confidence intervals and unfilled circles denoting data outwith the distribution.

exportable bulbs was based on only five samples. More thorough assessments of the ratio of exportable to nonexportable bulbs are needed to determine an appropriate scaling factor.

\section{Results}

\section{National survey of wild populations}

The 41 survey sites cover a total estimated area of 447 ha (Table 2), which represents c. $70 \%$ of the total area occupied by the national population (excluding populations in Abkhazia, which were not assessed). A number of apparently pristine, unharvested natural habitats for $G$. woronowii still exist and $20 \%$ of the total area of sites visited was determined to be of high conservation value (Table 1). We determined that $61 \%$ of the area of wild sites was of medium conservation value and $19 \%$ was of low conservation value. Most of the sites of low conservation value were those in which $G$. woronowii populations had become established in citrus plantations or other non-natural vegetation.

Wild sites had overlapping distributions of plant densities (Fig. 2), with an overall mean of 80 leaves per $0.25 \mathrm{~m}^{2}$ ( $95 \%$ CI $75-84$ leaves per $0.25 \mathrm{~m}^{2}$ ). Sites of high conservation value tended to have lower plant densities than those of medium and low conservation value (Kruskal-Wallis test, $\mathrm{P}<0.001$ ), although it is clear from Fig. 2 that these differences are not large.

\section{Survey of cultivated populations}

We surveyed c. 5 ha of cultivation sites, a small fraction of the total estimated area of c. 196 ha (Georgian Ministry of Environment Protection and Natural Resources, pers. comm.). Cultivation sites tended to have lower plant densities than the wild sites (Fig. 2; Kruskal-Wallis test, $\mathrm{P}<0.001)$. The mean leaf density of the commercially harvestable sites (excluding one site deemed a propagation failure) varied between 10.3 (range 6.8-13.9) and 129 (range 104.5-152.6) leaves per quadrat (Fig. 2). This variation partly reflects the fact that the sites were deliberately selected to cover a wider range of growing conditions and productivities.

A number of different cultivation methods were noted (Fig. 2). Most cultivated populations were intercropped with other annually harvested plants such as maize Zea mays L. and cabbages Brassica oleracea L. (Fig. 2). These tended to have lower plant densities, as did the one site where G. woronowii was planted under hazel Corylus sp., relative to the other cultivation systems (Fig. 2). A number of fields surveyed were dedicated solely to growing G. woronowii and tended to have higher plant densities (Fig. 2). The highest densities were found where G. woronowii was grown in deciduous woodland or citrus plantations (Fig. 2). We observed a significant but not large effect of the duration since the site was previously harvested on plant density: sites harvested 3 years previously tended to have higher plant densities than sites harvested 1 and 2 years previously, but 
TABLE 2 Survey data for wild populations of Galanthus woronowii in Georgia (Fig. 1), by district and region, with number of sites, total area of confirmed habitat, area by conservation value, estimated harvestable population, and estimated annual harvest.

\begin{tabular}{|c|c|c|c|c|c|c|c|}
\hline \multirow{2}{*}{$\begin{array}{l}\text { District (by region/ } \\
\text { Autonomous Republic) }\end{array}$} & \multirow{2}{*}{$\begin{array}{l}\text { No. of sites } \\
\text { surveyed }\end{array}$} & \multirow{2}{*}{$\begin{array}{l}\text { Total area of } \\
\text { confirmed } \\
\text { habitat (ha) }\end{array}$} & \multicolumn{3}{|c|}{$\begin{array}{l}\text { Area (ha) by conservation } \\
\text { value }\end{array}$} & \multirow{2}{*}{$\begin{array}{l}\text { Estimated harvestable } \\
\text { population (millions) }\end{array}$} & \multirow{2}{*}{$\begin{array}{l}\text { Estimated annua } \\
\text { harvest (millions }\end{array}$} \\
\hline & & & Low & Medium & High & & \\
\hline \multicolumn{8}{|l|}{ Ajara } \\
\hline Keda & 8 & 121 & 0 & 90 & 31 & 39.37 & 3.26 \\
\hline Khevalchauri & 12 & 135.3 & 56.3 & 55 & 24 & 57.91 & 8.19 \\
\hline Kobuleti & 5 & 53 & 8 & 25 & 20 & 21.68 & 1.68 \\
\hline \multicolumn{8}{|l|}{ Guria } \\
\hline Chokhatauri & 3 & 47 & 0 & 27 & 20 & 20.39 & 1.13 \\
\hline Lanchkhuti & 1 & 10 & 0 & 10 & 0 & 4.72 & 0.47 \\
\hline Ozurgeti & 1 & 15 & 0 & 15 & 0 & 5.32 & 0.53 \\
\hline \multicolumn{8}{|l|}{ Imereti } \\
\hline Kharagauli & 7 & 9.73 & 0 & 1.08 & 8.65 & 2.44 & 0.05 \\
\hline Vani & 3 & 50 & 0 & 50 & 0 & 9.68 & 0.97 \\
\hline \multicolumn{8}{|l|}{ Mtskheta-Mtianeti } \\
\hline Mtskheta & 1 & 6 & 0 & 0 & 6 & 1.94 & 0 \\
\hline Total & 41 & 447.03 & 84.3 & 273.08 & 89.65 & 163.45 & 16.29 \\
\hline
\end{tabular}

sites harvested $>3$ years previously had the lowest plant densities (Kruskal-Wallis test, $\mathrm{P}<0.001$ ).

Most cultivation sites were visibly different from the wild populations. They showed clear evidence of soil management and marked boundaries, all but the crop plants had been removed by weeding, and G. woronowii were often planted in the same field as other crop plants such as maize or cabbage. Generally the plants were more evenly spread throughout the field, in contrast to wild populations, which appeared to be more heterogeneous.

\section{Interview results}

Interviews with local traders, landowners and local government representatives revealed significant variation in the ages of the cultivation sites. Some were $>15$ years old, most were younger, and new sites were still being created by planting young bulbs in new fields (either by converting wild habitats or replacing other crops). The mother stocks of the plants in the cultivation sites were of various origins. The oldest sites had been planted with bulbs originating from wild populations in Turkey. Some younger sites had been planted with bulbs from wild populations in Georgia. Other sites had been planted with bulbs supplied by Georgian bulb companies, with unknown provenance. A number of sites had been planted from, or supplemented with, small bulbs originating in neighbouring fields or from adjacent wild populations. Bulbs harvested in Ajara were taken to a central holding warehouse in Batumi, where they were mixed with those from other sites, including bulbs of wild origin. Many sites in the Ajara region were apparently supplemented by bulbs from this warehouse that were deemed too small for export. Some cultivation fields existed in close proximity to wild G. woronowii populations, especially in the Ajara region. However, local traders suggested that harvest from the wild populations was not necessary because the bulbs grow well in the cultivation fields and that they would use the presence of $G$. woronowii in nearby wild populations as a suitability indicator for the establishment of new cultivation fields.

Together these findings implied that most, if not all, of the cultivation sites did not conform to the CITES definition of artificial propagation (CITES, 2012c), mainly because the effect of supplementary planting on the wild populations could not be established.

The decision to harvest the bulbs from a given cultivation site is determined by whether there are sufficient bulbs of exportable size $(>5 \mathrm{~cm}$ circumference) and whether the grower can sell the bulbs to a bulb export company. Bulbs are rarely harvested at a cultivation site 2 years in succession because it takes $>_{1}$ year for sufficient numbers of small bulbs to grow to exportable size. Many landowners indicated that they were willing to harvest some of their bulbs in 2009 if the bulb companies would buy them. However, none of the landowners interviewed sold bulbs to the bulb companies in 2008 and some suggested that the bulb companies obtained most of their bulbs for international export from wild populations that year. Local growers indicated that these harvests were not from the wild populations in their local area but from larger wild populations that were far from their villages.

\section{Population projections—wild populations}

We estimate there were c. 163 million plants with exportable bulbs at the 41 wild sites surveyed, covering an area of c. $447 \mathrm{ha}$, and that the area of sites represented in the national survey was c. $70 \%$ of the total area of the 
G. woronowii wild population in Georgia, giving an estimated total area of wild habitat of c. 639 ha (excluding Abkhazia) and an estimated total of 233 million exportable bulbs in the wild populations.

\section{Population projections—cultivated populations}

We estimate that there were c. 2.2 million exportable bulbs at 12 of the 15 cultivation sites visited (excluding a site deemed a propagation failure and two where no counts were made). The total area of the cultivation sites surveyed in 2009 was 7 ha, representing a relatively small fraction of the c. 196 ha of cultivation sites in Georgia (Georgian Ministry of Environment Protection and Natural Resources, pers. comm.). We therefore do not have a high degree of confidence in these projections. However, if the sites surveyed were representative then we estimate that there were c. 65 million exportable bulbs in the cultivation fields (using 2009 data only).

\section{Establishing a conservative export quota}

The final task of the review of significant trade was to establish a conservative export quota based on the inventory of standing stock and estimates of sustainable offtake. The quota was calculated based solely on the populations at the surveyed wild sites (163 million plants; Table 2 ) given that we only approximated the area of additional unsurveyed wild populations. We also excluded the estimated populations in cultivation fields given that $<4 \%$ of the estimated area of cultivation sites was surveyed.

Establishing a sustainable quota also required estimating a regeneration rate for the wild populations. Discussions with Georgian growers, bulb company representatives and Georgian botanists indicated that it takes c. 5 years for $G$. woronowii bulbs to attain harvestable size from seed. This is consistent with the general impression by experts that G. woronowii grows faster than the Turkish snowdrop G. elwesii, which takes c. 6 years (Arslan et al., 1997). However, not all bulbs are removed during harvesting. Ideally only harvestable-sized bulbs should be removed, to minimize the effect on the source population. If this practice is followed then populations usually recover from harvesting more quickly. In Turkey, where this method is employed to harvest wild $G$. elwesii populations, the same wild population can be harvested every 3 years without a long-term decline in abundance (Yüzbaşioğlu, 2008).

For G. woronowii harvesting in Georgia growers indicated that sites could recover after only 2 years. However, there is currently no other evidence to support this harvesting rate. We therefore recommended that wild sites were not re-harvested more frequently than every 3 years. This would imply that $33 \%$ of the harvestable bulbs could be harvested from the wild sites on a crop rotation basis, removing all harvestable bulbs from $33 \%$ of sites and not returning for 3 years. However, this disregards a number of other important factors such as the long-term effects of persistent harvesting on G. woronowii populations and the ecosystem. It is plausible, for example, that harvesting populations every 3 years could deplete the nutrient levels in the soil over longer timescales, and regular disturbance is also likely to alter the vegetation composition of the habitats.

Given these considerations we decided to adopt more precautionary harvest recommendations: harvesting would be banned from the surveyed wild sites of high conservation value (Tables 1 \& 2) to conserve those ecosystems, c. $10 \%$ of the area of surveyed wild sites of medium conservation value could be harvested in any one year, c. 20\% of the area of surveyed wild sites of low conservation value could be harvested in any one year, and cultivation sites could be harvested a maximum of every 3 years in accordance with our estimation of regeneration potential (although cultivation sites were not included in our estimation of a sustainable harvest quota, for the reasons noted above). Therefore, to calculate the annual quota we added $10 \%$ of the estimated harvestable population of surveyed medium conservation value sites to $20 \%$ of the estimated harvestable population of surveyed low conservation value sites, giving the estimated annual harvest (Table 2). Based on these precautionary assumptions we calculated that the surveyed wild sites alone could support a harvest of c. 16 million bulbs (Table 2 gives a breakdown by region and district), which is close to the historical figures for bulb exports from Georgia. Based on this information the CITES Scientific Authority made a non-detriment finding for G. woronowii, implemented through an annual quota of 15 million bulbs, with conditions on collection and management regimes.

\section{Discussion}

Georgia's wild G. woronowii populations appear to be widespread and relatively abundant after at least a decade of exports of 10-18 million wild-harvested plants per year. The populations are distributed throughout a variety of habitats with different levels of exposure to anthropogenic disturbance and management. Our evidence suggests that continuing the current levels of export is unlikely to be detrimental to the survival of the wild populations provided effective population and harvest monitoring and management are maintained. It also seems likely that higher harvest quotas could be justified through further research, given that our estimates were precautionary. Although our findings have clarified the nature of the harvesting of G. woronowii in Georgia, there remains uncertainty about the origins of the plants in the cultivation fields and the extent to which they can be harvested without being supplemented by wild bulbs. 
Our analysis implies that major stocks in cultivation fields and a more comprehensive survey of the cultivated populations would help to identify an appropriate harvest quota. If supplementary planting is necessary but does not have a detrimental effect on the survival of the species in the wild then a non-detriment finding could still be made and the sites could be treated as wild. The key concern here is that supplementary planting from wild populations could detrimentally affect the survival of those populations. Future surveys should therefore include the identification and monitoring of the wild source populations. A further survey of the cultivation sites in Georgia was conducted in 2010, after the completion of the CITES project described here, including some sites that had been harvested in 2009 (Fig. 2). It was found that the sites that had been harvested the previous year did not have significantly reduced densities of plants. According to the landowners, some of the sites had been incompletely harvested in 2009 and had recovered by asexual reproduction and some had been supplemented with plants from elsewhere (of unknown origin). However, the importance of supplementary planting from wild populations remains unknown.

There is significant national interest in managing the cultivation sites so that they conform to the CITES definition of artificial propagation. Georgia wants to establish a system of registered cultivation sites that fulfil the CITES definition of artificial propagation, which would allow exports above the national quota for wild material. The rights to this quota were purchased by a small number of exporters for a 10-year period, through a government auction scheme in 2008. The CITES Authorities instigated this scheme to help manage the then heavy demand for export permits. However, there has been increasing demand from traders outside the quota system for access to the market; hence the drive to produce artificially propagated material. A priority for further investigation will be to generate clear advice, based on experimental field trials, regarding the most effective ways to manage the cultivation and harvesting of bulbs to meet national priorities.

There could be a trade-off between ensuring that harvesting quotas are sufficiently precautionary to ensure that international trade is sustainable and allowing sufficiently large harvests to benefit local communities. Increasing the perceived value of wild populations may further encourage the protection of their habitats. Such a trade-off applies here: our precautionary approach to setting sustainable harvest quotas limits the potential benefits for local communities wishing to participate in the international trade and the potential value that could be placed on wild and cultivated populations. However, our findings clearly indicate some ways in which larger quotas could be justified: by identifying new source populations, through more detailed studies that facilitate less precautionary extrapolations, by establishing that cultivated populations do not detrimentally affect the survival of wild populations, or even by establishing cultivated populations that conform to the CITES definition of artificial propagation. In fact, in 2012 a system was established in Georgia whereby 20 cultivation sites were assigned the status of being artificially propagated. This allowed the export of $>3$ million bulbs above the quota.

Comparing the situation in Georgia with that of Turkey, which has been exporting artificially propagated G. elwesii and G. woronowii for international trade for some years, would provide better understanding of the relative costs and benefits of obtaining artificially propagated populations vs sustainable wild collection for species that appear to be relatively robust to harvesting. This could help to clarify the relative benefits of the different harvest and management options. Entwistle et al. (2002) provided some insights into potential difficulties associated with artificial propagation. They attempted to establish viable populations of G. elwesii in novel cultivation fields that were in close proximity to wild populations and could be harvested for international trade as artificially propagated. Although harvests for international trade were made, the long-term viability of the programme remained unclear because of declining yields from the cultivation fields as well as socio-economic factors.

Long-term experiments in harvesting cultivated and wild populations would help clarify their regeneration potential and effects of harvesting such as changes in the habitat of the wild populations or the potential for long-term decline in soil fertility. Ghimire et al. (2008) studied the effects of indigenous harvesting regimes of varying intensity on the demography of the medicinal herb Nardostachys grandiflora. Their study, combining 4 years of field experiments and modelling, generated insights into the consequences of differing harvesting intensities for the long-term effects of harvesting on populations. Based on their results they recommended different maximum harvesting rates for different habitats and a minimum return interval of at least 5 years.

The studies by Entwistle et al. (2002) and Ghimire et al. (2008) also highlighted the advantages of involving local harvesters in field studies. In Georgia such involvement could facilitate widespread and replicated field experiments and the development of guidelines that are applicable at a national scale. Our analysis implies potential benefits to G. woronowii growers and traders from research that would facilitate an increase in export quotas (less precautionary quotas). However, interviews with G. woronowii traders from Georgia (and comments from the Dutch bulb trade) indicated that a quota of 15 million plants per year currently satisfies market demand. This could explain why owners of cultivation fields struggled to sell their bulbs to traders, who could fulfil their quota by harvesting directly from wild populations.

One area of further research could be the investigation of alternative marketing mechanisms for cultivators. 
For example, obtaining fair-trade status for bulb cultivation initiatives, as was done for the cultivated G. elwesii in Turkey (Entwistle et al., 2002), may make the cultivated bulbs more competitive because these can typically attract a higher market price. The FairWild initiative (FairWild, 2012), which promotes the FairWild Standard and certification system for the sustainable management and collection of wild plants, may provide a model more suited to the Georgian situation, with true artificial propagation and the inherent high demands required by the CITES definition being limited in the long term to high-value cultivars and rare Georgian species of Galanthus, which are highly sought after by specialist collectors.

Rio+20, the United Nations Conference on Sustainable Development (UN, 2008), recognized that CITES stands at the intersection between trade, the environment and development and that it should contribute to tangible benefits for local people (CITES, 2012b). The trade in G. woronowii from Georgia stands at this intersection and further work is required to assess and enhance its value to local people. It is important to recognize all the stakeholders involved and work to promote sustainable use that provides a real benefit to local people, can operate effectively at a national and local level, and can be supported by the international community.

\section{Acknowledgements}

We thank the staff of the Biodiversity Protection Service of the Ministry of Environment Protection and Natural Resources of Georgia, representatives of the above Ministry in Ajarian Autonomous Republic and the regions of Guria and Imereti, and local residents for their assistance and support. We also thank the government of the Netherlands for the financial support for the project, the CITES Secretariat (in particular Milena Sosa Schmidt) for their assistance and support, and two anonymous reviewers for constructive comments.

\section{References}

Arslan, N., Koyuncu, M. \& Ekim, T. (1997) Commercial propagation of snowdrops (Galanthus elwesii Hook.) in different environments. Acta Horticulturae, 430, 743-746.

Bimmerman, A.J. (2000) Conservation and cultivation of some geophytes in Turkey and Georgia. Report of the third fact-finding mission to Turkey. Prepared for the EC Working Group of the CITES Scientific Authority.

Bishop, M., Davis, A. \& Grimshaw, J. (2001) Snowdrops: A Monograph of Cultivated Galanthus. Griffin Press, Maidenhead, UK

Cites (Convention on International Trade in Endangered Species of Wild Fauna and Flora) (1973) Text of the Convention. Http://www.cites.org/eng/disc/text.php [accessed 18 October 2013].
CITES (2012a) Resolution Conf. 12.8 (Rev. CoP13) Review of Significant Trade in specimens of Appendix-II species. Http://www.cites.org/eng/ res/12/12-08R13.php [accessed 18 October 2013].

CITES (2012b) Rio+2o recognizes the important role of CITES. Http:// www.cites.org/eng/news/pr/2012/20120627_RIO+20.php [accessed 18 October 2013].

CITES (2012c) Resolution Conf. 11.11 (Rev. CoP15) Regulation of trade in plants. Http://www.cites.org/eng/res/11/11-11R15.php [accessed 18 October 2013].

CONABio (Comisión Nacional para el Conocimiento y Uso DE LA Biodiversidad) (2008) International Expert Workshop on CITES Non-Detriment Findings, Cancun, Mexico. Http://www. conabio.gob.mx/institucion/cooperacion_internacional/ TallerNDF/taller_ndf.html [accessed 18 October 2013].

CoP11 (Conference of the Parties to Cites) (2000) Plants Committee, Report of the Chairman. Http://www.cites.org/eng/cop/ 11/doc/11_02.pdf [accessed 18 October 2013].

Entwistle, A., Atay, S., Byfield, A. \& Oldfield, S. (2002) Alternatives for the bulb trade from Turkey: a case study of indigenous bulb propagation. Oryx, 36, 333-341.

FAIR WILD (2012) FairWild Foundation. Http://www.fairwild.org/ [accessed 18 October 2013].

FFi (Fauna \& Flora International) (1999) CITES Significant Trade in Appendix II Species (Plants). Review of Trade in Galanthus and Cyclamen in Turkey and Georgia. Report prepared for the CITES Secretariat by FFI in association with DHKD and WWF-Georgia. FFI, Cambridge, UK.

FORD, P. (2008) The yin and yang of ginseng-making a non-detriment finding for Panax quinquefolius: a case study with two perspectives (United States of America). Http://www.conabio.gob.mx/ institucion/cooperacion_internacional/TallerNDF/LinksDocumentos/WG-CS/WG2-Perennials/WG2-CS6\%20Panax (USA-Canada)/WG2-CS6.pdf [accessed 18 October 2013].

Ghimire, S.K., Gimenez, O., Pradel, R., McKey, D. \& Aumeeruddy-Thomas, Y. (2008) Demographic variation and population viability in the threatened Himalayan medicinal and aromatic herb Nardostachys grandiflora: matrix modelling of harvesting effects in two contrasting habitats. Journal of Applied Ecology, 45, 41-51.

Greenwood, J.J.D. \& Robinson, R.A. (2006) Principles of sampling. In Ecological Census Techniques: A Handbook, 2nd edition (ed. W.J. Sutherland), pp. 11-85. Cambridge University Press, Cambridge, UK.

Grogan, J. \& Schulze, M. (2008) Estimating the number of trees and forest area required to supply internationally traded volumes of bigleaf mahogany (Swietenia macrophylla) in Amazonia. Environmental Conservation, 35, 26-35.

Kikodze, D. (2008) Assessing harvest levels for Galanthus woronowii Losinsk. in Georgia and the challenge of producing a Non-Detriment Finding. Http://www.conabio.gob.mx/institucion/ cooperacion_internacional/TallerNDF/Links-Documentos/WGCS/WG4-GeophytesandEpiphytes/WG4-CS2\%20Galanthuswo/ WG4\%20CS2.pdf [accessed 18 October 2013].

Kikodze, D., McGough, N., Smith, M., Wilford, R., Garrett, L., Memiadze, N. et al. (2009) Trade in Georgian snowdrops-A roadmap to sustainability. Unpublished report of CITES project No S302 Improving Implementation of CITES for Galanthus woronowii and Cyclamen coum from Georgia.

PC (CITES Plants Committee) (1997) Bulb trade from Georgia. PC8 Doc. 5.3. CITES, Geneva, Switzerland.

PC (2001) Harvesting techniques of Galanthus in Georgia. PC11 Doc. 9.1b. Http://www.cites.org/eng/com/pc/11/E-PC11-09-o1b.pdf [accessed 18 October 2013]. 
PC (2004) Summary record, fourteenth meeting of the Plants Committee, Windhoek, Namibia, 16-20 February 2004. Http://www.cites.org/eng/com/pc/14/E-Minutes-PC14.pdf [accessed 18 October 2013].

PC (2006a) Review of Significant Trade in specimens of Appendix-II species, species selected following CoP12, Galanthus woronowii. Http://www.cites.org/eng/com/pc/20/E20-14-01.pdf [accessed 18 October 2013].

PC (2006b) Summary record, sixteenth meeting of the Plants Committee, Lima, Peru, 3-8 July 2006. Http://www.cites.org/eng/ com/pc/16/E-PC16_summary_record.pdf [accessed 18 October 2013].

PC (2011) Addressing the challenges of making non-detriment findings for geophytes. Http://www.cites.org/eng/com/pc/19/e19-10-05.pdf [accessed 18 October 2013].

Rosser, A.M. \& Haywood, M.J. (eds) (2002) Guidance for CITES Scientific Authorities: checklist to assist in making non-detriment findings for Appendix II exports, 146 pp. IUCN, Gland, Switzerland and Cambridge, UK.

UN (United Nations) (2008) Goal 7: Ensure environmental sustainability. Http://www.un.org/millenniumgoals/2008highlevel/ pdf/newsroom/Goal\%207\%2oFINAL.pdf [accessed 18 October 2013].

YƯzbașioĞLu, S. (2008) The development of non-detriment findings for Galanthus elwesii Hook. F., in Turkey. Http://www.conabio.gob.mx/institucion/ cooperacion_internacional/TallerNDF/Links-Documentos/WGCS/WG4-GeophytesandEpiphytes/WG4-CS7\%20Galanthusel2/ WG4-CS7.pdf [accessed 18 October 2013].

\section{Biographical sketches}

Noel McGough coordinates Kew's role as UK CITES Scientific Authority for Plants and utilizes Kew's collections and expertise to promote sustainable use of plants and to build in-country capacity, projects and partnerships to implement CITES and the Convention on Biological Diversity. D A VID KI KO DZE's research interests encompass the taxonomy and geographical distribution of snowdrop species, plant conservation and invasive plant species. RICHARD WILFORD has experience in the cultivation of frost-hardy plants and has a particular interest in the taxonomy, cultivation and propagation of geophytes. LuCy GaRRETt has been involved in CITES research projects on non-detriment findings for plants, livelihood impacts and international trade patterns. GRIGOL DEISADZE assesses the effects of various developmental projects on flora and vegetation. NATALIE JAWORSKa completed an internship at the Royal Botanic Gardens, Kew where she supported work on researching and implementing CITES and the CBD. MAтTHEW SMIth is an ecologist and mainly works on creating useful, useable and defensible predictive models of ecological systems. 